\title{
Extracontractual referrals: the story so far
}

\author{
Preserving choice is costly
}

Since 1 April most treatments previously provided by district health authorities have been provided under block contracts between district purchasers and provider units. In addition, general practitioners have been able to refer their patients to provider units that have no contract with their patients' district of residence. These "extracontractual" referrals include emergencies and referrals for elective secondary and tertiary care (but not referrals of patients for treatments for which fundholders are financially responsible).

Along with general practitioner fundholding extracontractual referrals were considered the most unpredictable of the recent NHS reforms. Their number and their cost would affect purchasers and providers alike. Two papers in this week's journal provide an assessment of the working of the first three months of extracontractual referrals. ${ }^{23}$ Both conclude that the administrative workload that they entail is disproportionate to their number.

In preparation for the NHS changes health authorities had to decide whether the value of services that they intended purchasing from a provider justified the effort and cost of drawing up a contract. Their problem was that they lacked the data with which to make an informed decision. Most hospitals had no detailed breakdown of where their outpatients lived, and most health authorities were unaware of the care that their residents received outside their borders (especially true of long stay patients). Using their limited data health authorities applied average specialty costs, usually of the treating hospital, and then negotiated contracts with providers when the total cost of these services exceeded some chosen minimum.

Health authorities then had to decide how much money to put aside for extracontractual referrals. Some deliberately contracted with providers for activity levels below those of the previous year, intending either to reduce activity (and save money) or to allow for a margin of error in an uncertain world. This strategy hurt providers, who had included income from this source in their calculations of what services they could afford to provide.

Of the 15 districts in the South East Thames region only one set aside more than $2 \cdot 25 \%$ of its revenue budget for extracontractual referrals. At the other extreme two districts allowed only $0.8 \%$. By the end of June the whole region (looked at from the purchasing authorities' point of view) had marginally underspent its allocation for extracontractual referrals, although two districts had spent their first five months' allocation in three. Overall, the region's providers had experienced a slight drop in income (although the income of one provider fell by more than one fifth).

Knowing what these figures mean before the process of authorisation, investigation, treatment, and invoicing has settled down is difficult. Delays in treatment or invoicing for authorised referrals may mean cash savings for a commissioning authority in one year. Conversely, preferential treatment and speedy billing by providers could lead a purchasing authority prematurely to forecast an overspend. Linking approved extracontractual referrals and invoiced treatments should help purchasing authorities sort out where they are.

Williamson's personal commitment to adjudicating claims will surprise many consultants in public health medicine. ${ }^{3}$ While it is sensible for district general managers to ask district directors of public health to set up procedures for dealing with extracontractual referrals this should soon become an administrative task, performed within strict guidelines. District directors of public health should not be questioning clinical judgment unless it seems totally unjustifiable or perverse. After controversy over some purchasers' refusal to accept extracontractual referrals the NHS Management Executive has emphasised the importance of refusing only those referrals that are clinically unjustified or where general practitioners can be persuaded of a better alternative, taking into account the patient's views.

District health authorities, family health services authorities, and local providers should make general practitioners fully aware of the services for which contracts have been negotiated. This should minimise inappropriate extracontractual referrals arising from general practitioners' ignorance of what is available locally. Clinical consultants might be unaware of where their districts had placed contracts; even so, consultants in public health medicine would rarely want to challenge their tertiary referrals. Nor would it make sense for every district director of public health to create an inventory of all available specialised services. District directors of public health will want to monitor extracontractual referrals because they may indicate services that are deficient locally -in terms of either quality or availability-or that future contracts should provide.

Ghodse and Rawaf's paper raises several questions about emergencies. ${ }^{2}$ How do we decide whether an emergency was "genuine" and whether it was dealt with properly? Is it realistic, as some have suggested, to seek confirmation of the urgency of a particular case from the relevant general 
practitioner or consultant, perhaps even authorising an outpatient assessment for the purpose? When is treatment complete? Many urgent referrals may subsequently require further treatment or follow up.

The threat to patient confidentiality is the most disturbing feature of the whole process. Patients who are referred extracontractually may have their name, address, diagnosis, and proposed course of treatment transmitted, often by facsimile machine, to people not directly concerned with their care without their knowledge or consent (which they would probably withhold were they to be given the choice). What is needed is a simple, speedy method of transmitting information that preserves confidentiality. Some of the information that purchasing authorities are currently demanding suggests the need for national guidelines and a standard request form, with patients' identity being released only when general practitioners need contacting. Perhaps the patients' charter should include a sentence on the subject.

Ghodse and Rawaf write of extracontractual referrals as safeguarding the choice of patients and general practitioners, albeit at the cost of a considerable administrative workload. ${ }^{2}$ Williamson agrees about the workload and worries that the new procedures might restrict patient choice in the future. ${ }^{3}$ Three months is too early to decide: by 12 months we should have a better idea.

Regional Director of Public Health,

MALCOLM FORSYTHE

South East Thames Regional Health Authority,

Bexhill-on-Sea, East Sussex TN39 3NQ

1 NHS Management Executive. Circular FDL 90 34. London: NHS, 1990

2 Ghodse B, Rawaf S. Extracontractual referrals in first three months of NHS reforms. BMF 1991:303:497-9.

3 Williamson JD. Dealing with extracontractual referrals. B.Mf 1991:303:499-504.

\section{Vocational training in general practice}

\section{Time to take stock}

Many people have suggested that British general practice and vocational training have been something to be proud of and are even a "valuable export." But with the current changes to the health service the time has come to take stock and ask whether we are performing as well as we should be or whether vocational training is joining that long list of things that - like tennis and parliamentary democracy - may have been developed here but now seem to be done better elsewhere.

The scope of general practice is huge, and the job is changing rapidly with advances in care and altered social conditions. Thoughtful and creative publications, particularly by the Royal College of General Practitioners, ${ }^{2-4}$ have defined the training curriculum carefully. But new emphases are now needed. More specialised secondary care means that general practitioners must be even more proficient in helping patients to make sense of their illnesses, in responding to them at the level of primary care, and in integrating the care of patients with long term conditions. Although better understanding of the complexity of patients' presentations and needs has already informed vocational training, we are still reminded how often we fall down on the best standards of communication. ${ }^{56}$ Assessing the needs of groups or populations on the doctor's list using simple epidemiological methods should be part of a general practitioner's work. ${ }^{7} \mathrm{New}$ ideas about management should go beyond financial and organisational know how to include assessment and careful allocation of scarce resources such as colleagues' time, enthusiasm, and self confidence. Yet with so many pressing demands, how should the precious years of preparation for practice be spent?

After the undergraduate and preregistration period vocational training entails two further years in approved hospital posts and one year in a training practice. Properly constructed, this should be an engaging and challenging exploration, but for most that is not the case. The undergraduate curriculum remains largely hospital based and emphasises the individual acquisition of knowledge. Many of the courses are poorly integrated, with an imbalance between scientific and humanistic studies, and do not prepare the learner for a collaborative and self critical approach to a job in which lifelong learning is required. Newly qualified house staff often find themselves lacking crucial personal, scientific, and clinical problem solving skills. ${ }^{8}$

The requirement for three years' specialised training for general practice is much less than that for other specialties, yet the range of skills and knowledge that the practitioner needs to acquire is wider than that of the specialist. That only a little over one year out of nine or so as student and trainee is actually spent in general practice is extraordinary and could be supported only if the experience elsewhere was particularly good or if experience in practice itself was poor. But the reverse is true. During the years spent in hospital much of the work is routine and of doubtful relevance to general practice. Several studies have shown the damaging effects of long hours on call, ' lack of sleep, and emotional stress on doctors' care of patients, their personal lives, and their future attitudes. ${ }^{10}$ For some doctors the consequences have been lethal. " This rite of passage might be worth arguing for if the standard of education was high: yet one study has shown no formal teaching in over one third of posts, with $85 \%$ of trainees receiving formal training for less than two hours a week. ${ }^{12}$ Over half the respondents to a national trainee conference survey in 1989 had no teaching oriented towards general practice in their last hospital post. ${ }^{13}$ Personal supervision is not a strength of the hospital style and appears to have diminished with recent manpower changes and bed cuts. Attendance at half day release courses is patchy when it should be mandatory.

Unsurprisingly, after these experiences learners are far more satisfied with their year in practice. Trainees enter this time with relief and raised expectations. Compared with those in hospitals, teaching standards in practices and training schemes are high, with reasonable levels of supervision. Vocational training for general practice is probably well in front of training elsewhere in the health service and remains an important model. Often, however, training recommendations are not fully adhered to,${ }^{14}$ and considerable room for improvement still exists. The apprentice model has its weaknesses, and trainees should acquire broader experience in primary care. Trainees are not taught skills in evaluating their own work and are not good at assessing published work-a defect that the new MRCGP exam is addressing. ${ }^{15}$ 